\title{
Research Trends in Mobile Learning in Higher Education: A Systematic Review of Articles (2011 - 2015)
}

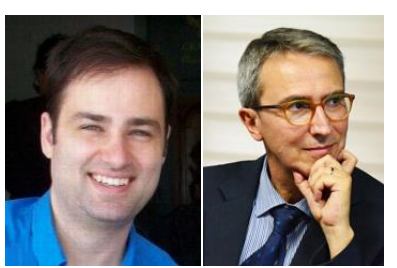

Greig Krull and Josep M Duart

Universitat Oberta de Catalunya

\begin{abstract}
The potential and use of mobile devices in higher education has been a key issue for educational research and practice since the widespread adoption of these devices. Due to the evolving nature and affordances of mobile technologies, it is an area that requires ongoing investigation. This study aims to identify emerging trends in mobile learning research in higher education in order to provide insights for researchers and educators around research topics and issues for further exploration. This study analysed the research themes, methods, settings, and technologies in mobile learning research in higher education from 2011 to 2015. A total of 233 refereed articles were selected and analysed from peer reviewed journals. The results were compared to three previous literature review-based research studies focused between 2001 and 2010 to identify similarities and differences. Key findings indicated that: (a) mobile learning in higher education is a growing field as evidenced by the increasing variety of research topics, methods, and researchers; (b) the most common research topic continues to be about enabling m-learning applications and systems; and (c) mobile phones continue to be the most widely used devices in mobile learning studies, however, more and more studies work across different devices, rather than focusing on specific devices.
\end{abstract}

Keywords: mobile learning, research trends, research methods, pedagogical issues, higher education

\section{Introduction}

Many higher education institutions are implementing mobile learning to provide flexibility in learning. It is expected that this will continue to be a growing trend with the proliferation of wireless devices and technologies. It is expected that the next generation of mobile learning will be ubiquitous and learners themselves will be more mobile and able to learn using multiple devices (Ally \& Prieto-Blázquez, 2014). Although there are a number of interpretations of what is meant by mobile learning, this study makes 
use of the definition by O'Malley et al. (2005) as "any sort of learning that happens when the learner is not at a fixed, predetermined location, or learning that happens when the learner takes advantage of the learning opportunities offered by mobile technologies." (p. 7).

Mobile devices tend to drive new research opportunities in mobile learning because of the rate of changes in technologies. In addition to devices, communication technologies have also changed, shifting the focus of research (Parsons, 2014). For example, social media and messaging "apps" are commonplace. The development and usage patterns of mobile technologies in education change quickly. This means that regular analysis is required of "trends in mobile device types and functionality, along with learner types and the use of mobile devices in various disciplines and courses" (Wu et al., 2012, p. 818). The research purposes and methods used in studies are important because they influence how research results are shared, interpreted and used (Wingkvist \& Ericsson, 2011). Review studies can help to identify progress in the field and offer guidelines for the design of future research (Frohberg, Göth, \& Schwabe, 2009). Understanding the trends in research studies can also help higher education policy makers in making decisions regarding technology and teaching and learning (Wu et al., 2012).

This paper provides a systematic review of mobile learning research in higher education from 2011 to 2015. It begins with an analysis of previous review studies in order to provide the basis of comparison with similar studies. The research purpose and questions are then described. The next section discusses the methodology used to conduct the review study. This is followed by the presentation of the results of the study, with a comparison to three previous studies. The final section provides a discussion of the findings of the review study.

\section{Previous Studies}

A number of review studies have been conducted in recent years in an attempt to explore and provide insights into the growing body of knowledge in mobile learning. One of the first reviews in mobile learning provided an activity-focused perspective of case studies in the use of mobile technologies for education (Naismith, Lonsdale, Vavoula, \& Sharples, 2004). Cheung and Hew (2009) conducted a review of research methodologies used in mobile learning in school and higher education settings. They reviewed 44 articles published until the end of 2008 and found that descriptive research was the most dominant research method and questionnaires were the most used data collection method. Frohberg, Göth, and Schwabe (2009) conducted a review of 109 mobile learning projects to evaluate and categorise them against a mobile learning task model. Hwang and Tsai (2011) conducted a study of research trends in mobile and ubiquitous learning by reviewing 154 articles from six major technology-enhanced learning journals from 2001 to 2010. They found that the number of studies increased significantly over the period. They also found that higher education students were the most frequent learning populations and that most studies did not focus on a specific learning domain. Hung and Zhang (2012) examined mobile learning trends between 2003 and 2008 by using text-mining techniques to conduct a metatrend analysis of 119 articles. They similarly found that studies in mobile learning increased rapidly over that period. They also found that many studies focused on the effectiveness of mobile learning but there was increasing focus on evaluation and systems development. Wu et al. (2012) recognised the value of these two previous studies, but felt further examination was required "from the standpoint of research purposes, methodologies, and outcomes" (p. 817). The authors used a meta-analysis approach to 
systematically review 164 mobile learning studies published between 2003 and 2010. They also found most research purposes focussed on effectiveness and system design, but also found that surveys and experimental methods were the most used research methods and that the research outcomes in studies were significantly positive.

Systematic reviews have also been conducted on conference proceedings. Wingkvist and Ericsson (2011) surveyed 114 papers presented at the World Conference on Mobile Learning (mLearn) conferences in 2005, 2007, and 2008. The focus of the review was on research purposes and research methods. They found that research methods were evenly distributed, with the exception of basic research (development of new theories). In terms of research purpose, the majority of papers were descriptive research, followed by developmental and understanding research. The lack of evaluative research papers was found to be a problem (Wingkvist \& Ericsson, 2011).

A number of review studies have also been conducted to investigate a particular aspect or theme related to mobile learning. Wong and Looi (2011) conducted a review of mobile-assisted seamless learning related literature between 2006 and 2011. Baran (2014) studied the literature to "fill the gap" on mobile learning research in teacher education programmes. Song (2014) investigated methodological issues in Mobile Computer-Supported Collaborative Learning (mCSCL) research between 2000 and 2014. Liu et al. (2014) reviewed 63 articles in K-12 education between 2007 and 2012. Hsu and Ching (2015) reviewed 17 articles to categorise the models and frameworks developed specifically for mobile learning. Alrasheedi and Capretz (2015) reviewed 19 articles to determine critical success factors affecting mobile learning.

Parsons (2014) noted the number of previous reviews, yet highlighted that most reviews tended to focus on a specific subset of the literature or a particular aspect of mobile learning. The purpose of his study was to "provide a full-landscape view of the field of mobile learning" up to and including 2013 (p. 2). Findings were presented in two forms. A timeline was used to highlight the evolution of mobile learning through a series of significant "firsts." Secondly, a mind map was used to summarise the key concerns in the areas of research, technology, content, learning, and learner (Parsons, 2014).

\section{Research Problem}

The number of literature review-based studies and the results of these studies indicate a research field that is growing and changing. Due to developments in technology, it is worth considering how the field of mobile learning research is changing and how these studies are applied in higher education specifically. Although several review studies (Hwang \& Tsai, 2011; Wu et al., 2012) have found that the majority of mobile learning studies take place within higher education, very few mobile learning review studies have focussed solely on this sector. This study aims to analyse the research topics, methods, settings, and technologies used in mobile learning research in higher education, published from January 2011 to December 2015. The research questions are:

1. What research methods have been used in mobile learning articles published from 2011 to 2015 ?

2. What are the research trends in terms of purposes, themes, and technologies? 
3. How do the findings relate to previous mobile learning reviews from 2001 to 2010 ?

\section{Methodology}

A systematic review provides a summary of the research literature, either quantitative or qualitative, that uses explicit, replicable methods to identify and select relevant studies; and uses objective and replicable techniques to analyse and summarise those studies (Cooper, 2010, as cited in Bernard, Borokhovski, \& Tamim, 2014). In order to ensure a systematic review process, this study followed the seven steps suggested by Cooper (2010, as cited in Bernard et al., 2014) for conducting a systematic review or meta-analysis:

1. Formulate the research problem.

2. Search the literature.

3. Gather information from studies.

4. Evaluate the quality of studies.

5. Analyse and integrate the outcomes of research.

6. Interpret the evidence.

7. Present the results.

These stages are neither mutually exclusive nor entirely distinct; rather, they should be viewed as key steps in a continuous and iterative process (Cooper, 2010, as cited in Bernard et al., 2014). The first step in conducting a systematic review is to formulate the research problem, which has been specified in the section above.

\section{Literature Search}

The second step in a systematic review is to search the literature. A limitation may exist in this study, referred to as publication bias (Bernard et al., 2014), as this study has not surveyed the "grey literature" such as conference proceedings, technical reports, dissertations, and book chapters. However, the search was limited to peer reviewed journal articles in order for better comparison between sources and aligns with the search strategies by Hwang and Tsai (2011), Wu et al. (2012), Baran (2014), and Bozkurt et al. (2015). Based on these studies, two databases were selected to ensure comprehensive data collection: Scopus and ISI Web of Science. The starting point involved searching for a combination and variation of the keywords "mobile learning" or "m-learning" and reviewing the results against the following inclusion criteria:

- Must involve mobile learning as a primary condition,

- Must focus specifically on learning at the higher education level,

- Must be published in a peer reviewed journal between January 2011 and December 2015,

- Must be written in English, and 
- The full-text of the article must be publically available or available through the researchers' institutional library subscriptions.

The first database searched was Scopus. A search of the keywords "mobile learning," "m-learning," or "mlearning" in articles published between 2011 and 2015 resulted in 1024 results. The results were filtered to remove non-journal sources (955 results remained) and non-English texts (937 results remained). The researchers then discarded 373 results because they did not have access to the full text. The remaining 564 results were assessed against the criteria that the primary focus of the article was mobile learning and within higher education. A total of 348 articles did not meet these criteria, leaving 216 articles to be included in this study.

The second database searched was the ISI Web of Science (SCI/SSCI). A search of the keywords "mobile learning," "m-learning," or "mlearning" in articles published between 2011 and 2015 resulted in 1703 results. The results were filtered to remove non-journal sources (698 results remained) and non-English texts ( 578 results remained). The researchers then discarded 254 results because they did not have access to the full text. The remaining 324 results were assessed against the criteria that the primary focus of the article was mobile learning and within higher education. One hundred and sixty-nine articles did not meet these criteria, leaving 155 articles to be included in this study. These were compared to the results of the previous database search, and 138 duplicates were excluded and 17 results were added, resulting in a total of 233 articles to be studied.

\section{Information Gathering}

The third and fourth steps in conducting a review are to gather the information from studies and evaluate the quality of studies. The 233 articles were collected and organised with the bibliographic data including article title, authors, journal, abstract, keywords, and publication year. Eleven additional categories related to the articles were coded, based on the studies of Hwang and Tsai (2011), Wu et al. (2012), Baran (2014), and Bozkurt et al. (2015). The categories were: (a) research purpose, (b) research theme, (c) conceptual and theoretical background, (d) research method, (e) research design, (f) data collection method, (g) target population, (h) learning domain/discipline, (i) learning setting, (j) type of device, and (k) country. Two independent researchers then independently confirmed the coding for the first six categories. Disagreements between the two coders were resolved through discussion and further review of the disputed studies by the principal researchers. This review study targeted peer-reviewed journal articles, which helps to ensure the relative rigour and quality of studies under review (Hsu \& Ching, 2015). The spreadsheet matrix with the 233 categorised articles can be accessed online.

\section{Research Analysis}

The fifth step is to analyse and integrate the outcomes of research. This study made use of content analysis to analyse the data. Content analysis is a method of analysing documents and enables the researcher to test theoretical issues to enhance understanding of the data (Elo \& Kyngäs, 2008). Content analysis can use a mix of quantitative and qualitative methods so that a combination of bibliometric and categorical data can be used to reveal trends (Hung \& Zhang, 2012). In order to answer our third research question, the results were then compared to the results of this study with three previous literature review studies (Hung \& Zhang, 2012; Hwang \& Tsai, 2011; Wu et al., 2012). It must be noted that a direct comparison cannot be performed with each aspect of the studies due to differences in the 
approaches, timing, and methods used in this study, but that a useful comparison may still be drawn between these studies.

Steps 6 and 7 of the systematic content review process are to interpret the evidence and present the results. The next section of the paper presents the outcomes of this process. Two hundred and thirtythree articles on mobile learning in higher education published from 2011 to 2015 were included in this sample: for 2011 - 22 articles; for $2012-38$ articles; for 2013 - 45 articles; for 2014 - 68 articles; and for $2015-60$ articles. The frequency of papers is apparent in the sample increase for each year under study, except for the last.

\section{Journals}

These articles were published in 88 different journals. Table 1 shows the frequency of articles from journals that have three or more articles in this study. Those journals that are open access are denoted with an OA in brackets after the journal name.

Table 1

Distribution of Journals With Three or More Articles in This Study

\begin{tabular}{|r|l|r|}
\hline Rank & Journals & Frequency \\
\hline 1 & Computers \& Education & 19 \\
\hline 2 & The International Review of Research in Open and Distributed & 18 \\
\hline 3 & Educational Technology \& Society (OA) & 13 \\
\hline 3 & International Journal of Interactive Mobile Technologies (OA) & 13 \\
\hline 5 & Computers in Human Behavior & 12 \\
\hline 5 & Turkish Online Journal of Educational Technology (OA) & 12 \\
\hline 7 & British Journal of Educational Technology & 11 \\
\hline 7 & Journal of Universal Computer Science (OA) & 11 \\
\hline 9 & The Turkish Online Journal of Distance Education (OA) & 7 \\
\hline 10 & Australasian Journal of Educational Technology (OA) & 5 \\
\hline 10 & Electronic Journal of e-Learning (OA) & 5 \\
\hline 10 & IEEE Transactions on Learning Technologies & 5 \\
\hline 13 & International Journal of Mobile and Blended Learning & 4 \\
\hline 13 & Research in Learning Technology (OA) & 4 \\
\hline 15 & Journal of Asynchronous Learning Networks & 3 \\
\hline 15 & Nurse Education Today & 3 \\
\hline 15 & Language Learning and Technology (OA) & 3 \\
\hline & The International Journal of Educational Technology in Higher & 3 \\
\hline 15 & Education (OA) & \\
\hline
\end{tabular}

\section{Countries}

This study represented a wide range of developed and developing countries, for a total of 45 countries. Country categorisation was based on the country where the research was conducted, rather than the researcher's affiliation. The countries with the most number of studies represented were United States (26), United Kingdom (25), Taiwan (21), Spain (16), and Turkey (16). In terms of comparison with studies from 2001-2010, these findings closely align to the findings of Hwang and Tsai (2011). In their study, they found that the three countries that contributed the most number of studies were the United States, Taiwan, and the United Kingdom, which is the same in this study. Hung and Zhang (2012) also found the top two contributors to be Taiwan and the United States, although South Korea was third in 
their study. As an indication of the expansion of the field of mobile learning, the articles in the study by Hwang and Tsai (2011) represented studies conducted in 25 countries, while in this study, 45 countries were represented.

\section{Results}

\section{Research Purposes}

Each article was categorised according to its research purpose, adapted from the classification presented by Wu et al. (2012). The original four purposes were: (1) Evaluate Effectiveness, (2) Design a Mobile System, (3) Investigate the Affective Domain, or (4) Evaluate the Influence of Learner Characteristics. A similar classification was provided by Hsu and Ching (2015). Two additional categories were added by the researchers for this study: (5) Develop Theory and (6) Explore Potential, in order to better represent all possible purposes. These categories were then defined as:

- Evaluate the effects: investigates whether mobile devices can improve or enhance student learning.

- Explore the potential: explores how to use a new tool or how a new technology could be used for learning (usually a small pilot or exploratory study).

- Investigate the affective domain: investigates the affective domain includes factors such as student motivation, beliefs, attitudes, perceptions, and values.

- Design a system: designs frameworks or systems where the emphasis is on the development and presentation of solutions.

- Develop theory: create or promote new pedagogical approaches, models, theories, or frameworks of mobile learning.

- Influence of learner characteristics in the learning process: examines the influence of learner characteristics such as age, gender, ability, experience, learning style, and culture.

As shown in Figure 1, the most common research purpose was found to be to evaluating effectiveness (24\%), followed by designing a mobile system (23\%), and investigating the affective domain (19\%). In terms of comparison with 2001-2010, these findings are similar to those of Wu et al. (2012) in that evaluating effectiveness was the most common method, followed by designing a mobile system. However, studies investigating the affective domain, previously a very small research purpose in terms of the number of studies, have become a greater point of focus. 


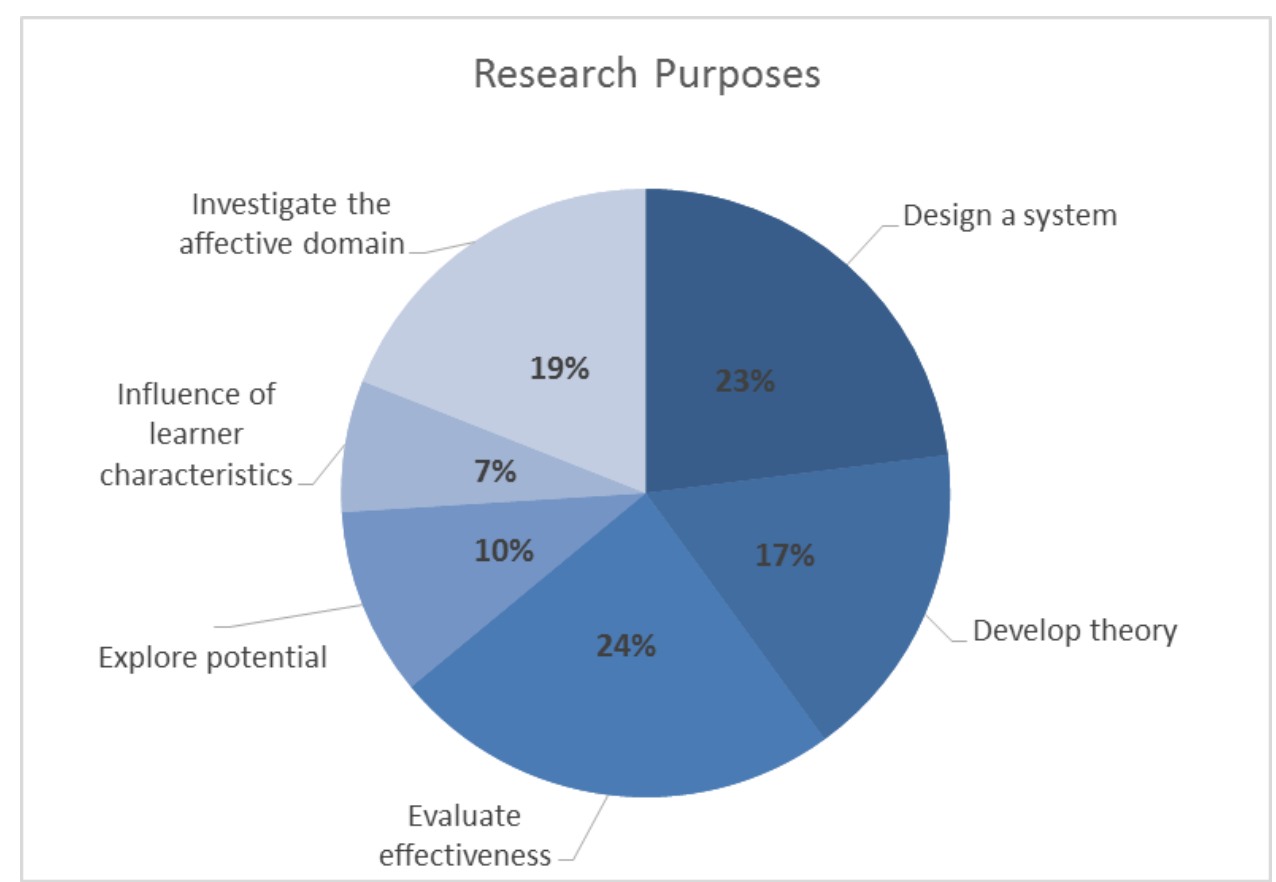

Figure 1. Distribution of studies by research purpose.

\section{Themes}

It is difficult to find a common list of themes within mobile learning as the categorisation of mobile learning research depends on the focus of the interests of the researchers (Parsons, 2014). For example, researchers such as Parsons (2014) and Hsu, Ching, \& Snelson (2014) have provided different categorisations. In this study, the researchers decided to adapt the themes proposed by the annual International Conference on Mobile Learning Conference themes (http://mlearning-conf.org/). Figure 2 shows the distribution of research themes in studies from 2011-2015. Although several articles contained overlapping themes, each article was categorised into one major theme for the purpose of this review. Studies covered a wide range of themes within mobile learning in higher education. The most common research theme focused on enabling m-Learning applications and systems (23\%), followed by socio-cultural context and implications of m-Learning (13\%), and tools and technologies for m-Learning (12\%). No comparison can be done with the research studies from 2001-2010 as the research themes as categorised in this study were not within the scope of the studies of Hwang and Tsai (2011), Hung and Zhang (2012), and Wu et al. (2012). 


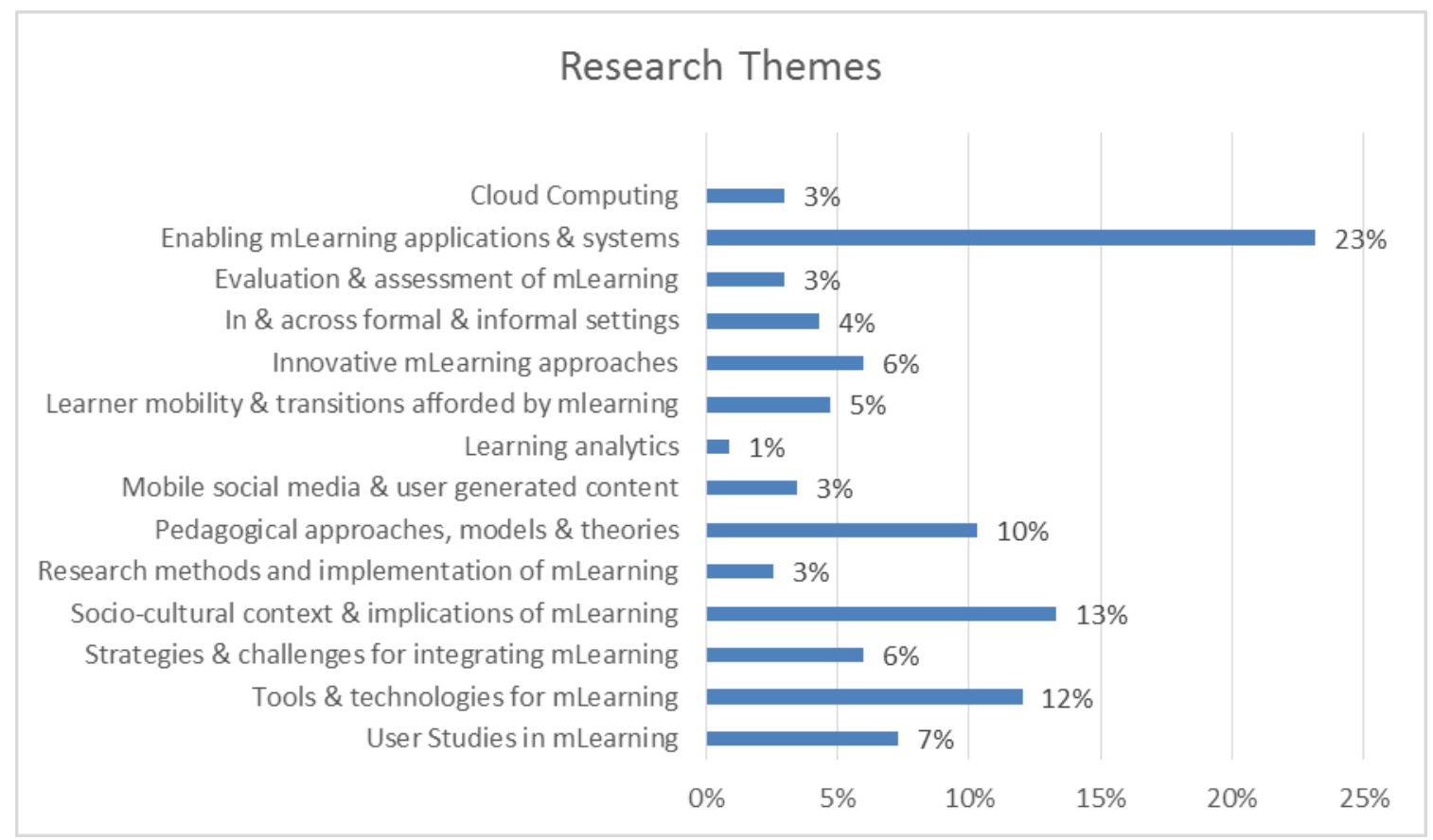

Figure 2. Distribution of studies by research theme.

Researchers continue to investigate a wide variety of research themes or topics. The most common research theme for mobile learning in higher education is the wide variety of applications and systems that are used to enable learning. Existing systems such as text messaging can be used to communicate with or support students (Lim, Fadzil, \& Mansor, 2011) or custom applications can be designed for specific subjects ( $\mathrm{Wu}, 2015)$. The next most common theme is the exploration and use of new tools and technologies for mobile learning. These include specific devices such as smartphones (Gikas \& Grant, 2013), tablets (Churchill \& Wang, 2014; Engin \& Donanci, 2015) and other devices. Researchers are also interested in the social and cultural contexts that surround mobile learning (Arpaci, 2015; Viberg \& Gronlund, 2013). Educators are exploring how to use social media such as Twitter (Hsu \& Ching, 2012) for learning. Researchers are also developing pedagogical approaches or theories for mobile learning (Dennen \& Hao, 2014; Park, 2011). Other researchers have provided strategies for integrating mobile learning and overcoming challenges to mobile learning implementation (Brown \& Mbati, 2015; Cochrane, 2014). A few studies have also examined differences in learners and faculty by studying users within mobile learning (Mac Callum, Jeffrey, \& Kinshuk, 2013; Lin, Zimmer, \& Lee, 2013). Educators are also interested in learning within classes and out of classes. In-class systems may include student response systems (Calma, Webster, Petry, \& Pesina, 2014), while researchers are also interested in informal learning outside of classrooms (Reychav, Kobayashi, \& Dunaway, 2015). Innovative learning approaches include a variety of different approaches. Studies have used context-aware mobile learning services to personalise learning (Lu, Chang, Kinshuk, Huang, \& Ching-Wen, 2014; Wu, Hwang, Su, \& Huang, 2012) or made use of mobile augmented reality (Fonseca, Martí, Redondo, Navarro, \& Sánchez, 2014). The use of gamification has been used to promote motivation (Bartel \& Hagel, 2014). Learner mobility studies have focused on learners using devices for collaborative learning in the field (Redondo, Fonseca, Sánchez, \& Navarro, 2014). Another area of interest for educators and researchers is the use of assessment and evaluation. For example, integrating the use of mobile quizzes into learning processes (Bogdanović, Barać, Jovanić, Popović, \& Radenković, 2014). Researchers have focused on integrating cloud computing into mobile learning (Wang, Chen, \& Khan, 2014). Researchers have also investigated how mobile learning is researched and implemented, through review studies (Baran, 2014). With 
increasing amounts of data available, educators are interested in using learning analytics to understand and optimise learning processes and environments (Tabuenca, Kalz, Drachsler, \& Specht, 2015).

\section{Theoretical and Conceptual Backgrounds}

Every research study should have clear theoretical or conceptual backgrounds (Bozkurt et al., 2015). In classifying the theoretical and conceptual backgrounds specified in research articles, insights may be provided regarding the kinds of topics and how researchers are approaching them in mobile learning in higher education. Where stated, the theories and or concepts stated in the articles were included in the categorisation, adapted from the classification by Bozkurt et al. (2015). Table 2 lists the most frequently stated theories or underlying concepts. In several articles, multiple theoretical or conceptual backgrounds were used together; however, Table 2 only highlights the frequency of the theoretical or conceptual backgrounds in the population.

The most frequently stated theoretical or conceptual backgrounds model how users come to accept and use a new technology (Technology Acceptance Model (TAM), Unified Theory of Acceptance and Use of Technology (UTAUT), and Diffusion of Innovation). A strong emphasis can be seen on collaboration within a community (Collaborative Learning, Communities of Practice). Another trend can be seen to be moving to a learner-oriented paradigm focussing on student experiences in a social world (Activity Theory, Social Constructivism, Constructivism) and authentic learning experiences (Authentic Learning). With the affordances of mobile technologies leading to educators redesigning their curricula or modes of provision, instructional design theories are also important (Cognitive Load Theory, Instructional Design).

Table 2

Distribution of Most Common Theoretical or Conceptual Backgrounds

\begin{tabular}{|r|r|r|}
\hline Rank & Theoretical / Conceptual background & Frequency \\
\hline 1 & Technology Acceptance Model (TAM) & 23 \\
\hline 2 & Unified Theory of Acceptance and Use of Technology & \\
\hline 3 & Collaborative Learning & 6 \\
\hline 4 & Activity Theory / Systems & 5 \\
\hline 4 & Cognitive Load Theory & 5 \\
\hline 4 & Diffusion of Innovation & 5 \\
\hline 4 & Self-regulated / Self-managed Learning & 5 \\
\hline 8 & Authentic Learning & 4 \\
\hline 8 & Communities of Practice & 4 \\
\hline 8 & Learning Styles & 4 \\
\hline 8 & Scaffolded Learning & 4 \\
\hline 8 & Social Constructivism & 4 \\
\hline 8 & Socio-cultural Theory & 4 \\
\hline & Technological Pedagogical And Content Knowledge & \\
8 & (TPACK) & 4 \\
\hline 15 & Adaptive Learning & 3 \\
\hline 15 & Constructivism & 3 \\
\hline 15 & Cultural Dimensions & 3 \\
\hline 15 & Instructional Design & 3 \\
\hline & Substitution Augmentation Modification Redefinition & \\
15 & (SAMR) & 3 \\
\hline
\end{tabular}


No comparison can be done with the research studies from 2001-2010 as the theoretical and conceptual background was not a specific focus of the studies of Hwang and Tsai (2011), Hung and Zhang (2012), and Wu et al. (2012).

\section{Research Designs}

A mobile learning study generally employs a quantitative, qualitative, or mixed research method like other educational fields (Bozkurt et al., 2015). In this review, researchers in mobile learning in higher education mostly conducted qualitative research (46\%) or quantitative research (43\%), with fewer studies employing mixed methods (11\%). No comparison can be done with the research studies from 2001-2010 as the research method was not a specific focus of the studies of Hwang and Tsai (2011), Hung and Zhang (2012), and Wu et al. (2012).

In addition to the research method, the research design can also be explored within each of the methods. The methods used to categorise the research were adapted from Bozkurt et al. (2015) and Creswell (2009). Table 3 indicates that the most commonly used research designs for quantitative studies were descriptive surveys (17\%), followed by correlational studies (13\%), and experiments (12\%). Table 3 also indicates that the most commonly used research design for qualitative studies was design-based research (18\%), followed by case studies (17\%), and action research (3\%). For mixed methods, the most common research designs used were sequential explanatory (7\%), concurrent triangulation (3\%), and sequential exploratory (1\%).

Table 3

Distribution of Studies by Research Design

\begin{tabular}{|l|r|l|r|l|r|}
\hline \multicolumn{2}{|c|}{ Quantitative (43\%) } & \multicolumn{2}{c|}{ Qualitative (47\%) } & \multicolumn{2}{c|}{ Mixed (11\%) } \\
\hline Case Study & $1 \%$ & Action Research & $3 \%$ & $\begin{array}{l}\text { Concurrent } \\
\text { Triangulation }\end{array}$ & $3 \%$ \\
\hline Correlational & & & & $\begin{array}{l}\text { Sequential } \\
\text { Explanatory }\end{array}$ & $7 \%$ \\
\hline Experiment & $13 \%$ & Case Study & & $\begin{array}{l}\text { Sequential } \\
\text { Exploratory }\end{array}$ & $1 \%$ \\
\hline Survey & $12 \%$ & Content Analysis & $3 \%$ & & \\
\hline & $17 \%$ & Design-based & $18 \%$ & & \\
\hline & & Grounded Theory & $1 \%$ & & \\
\hline
\end{tabular}

In terms of comparison with 2001-2010, the quantitative method findings closely align to the findings of Wu et al. (2012). They found the most common methods for quantitative studies to be experiments and descriptive research. However, the qualitative methods are different in that Wu et al. (2012) did not find case studies, action research, nor other qualitative methods to be widely used. A caution must be noted though that Wu et al. (2012) presented their results with a different classification and integrated the presentation of results for both research methods and data collection methods.

\section{Data Collection}

Data collection methods were also investigated in this study. Methods were coded into seven categories, adapted from Song (2014) and Cheung and Hew (2009). Table 4 shows that the most common method used was a survey (47\%) followed by interviews/focus groups (18\%) and assessments (13\%). Studies utilised between one and five data collection methods, with $57 \%$ of studies utilising one method and $28 \%$ 
of studies utilising two methods. Twelve percent of studies utilised three methods, while $3 \%$ utilised four methods.

Table 4

Distribution of Studies by Data Collection Method

\begin{tabular}{|l|l|l|}
\hline Method & Instruments or techniques & Frequency \\
\hline Assessment & Tests or quizzes & $13 \%$ \\
\hline Document Review & Examination of documents & $5 \%$ \\
\hline $\begin{array}{l}\text { Interviews/Focus } \\
\text { Groups }\end{array}$ & Discussions between researchers, staff, or students & $18 \%$ \\
\hline Observation & $\begin{array}{l}\text { Visual examination and documenting actions and utterances of } \\
\text { participants, either directly or via recording }\end{array}$ & $3 \%$ \\
\hline Process Data & $\begin{array}{l}\text { Estimates of time, frequency and sequence as well as tracing } \\
\text { data and learning analytics obtained from systems and devices }\end{array}$ & $6 \%$ \\
\hline Product Data & $\begin{array}{l}\text { All outputs produced by participant activities such as course } \\
\text { assignments }\end{array}$ & $7 \%$ \\
\hline Survey & Questionnaires, surveys, and scales & $47 \%$ \\
\hline
\end{tabular}

In comparison with studies from 2001-2010, the collection method findings do align somewhat to the findings of Wu et al. (2012) in that surveys continue to be the most common format of collecting data. However, the current study results seem to indicate that a wider range of data collection methods were used (2011-2015) than previously.

\section{Population Groups}

It was found that the vast majority of studies were aimed at students (78\%). A few studies focused on faculty (10\%) or a combination of both faculty and students (12\%). Of the studies that focused on students, 75 studies distinguished between undergraduate and postgraduate levels of students. Of these studies, $81 \%$ studies focussed on undergraduates and $19 \%$ focused on postgraduate students. As both faculty and student adoption play a part in the success of mobile learning initiatives, it is recommended that more studies in the future look to investigate the implications for both faculty and students. A major difference between this study and previous studies by Hwang and Tsai (2011) and Wu et al. (2012) is that this study only focused on the higher education sector. However, both Hwang and Tsai (2011) and Wu et al. (2012) similarly found that the majority of mobile learning studies across all sectors focused on higher education students.

\section{Academic Disciplines}

Wu et al. (2012) define an academic discipline as a branch of knowledge that is taught or researched at the higher education level. This study follows the discipline taxonomy used by Wu et al. (2012) who adopted it from the taxonomy developed by Becher (1994), Wanner, Lewis, and Gregorio (1981), and others. This taxonomy identifies five major categories of academic discipline: humanities, social sciences, natural sciences, formal sciences, and professions and applied sciences. Academic subjects listed in the Classification of Instructional Programs (CIP) (Institute of Education Sciences, 2010) can be classified within these disciplines. These disciplines and subjects are listed in Table 5. A third (33\%) of mobile learning studies in higher education are across disciplines (generic) or not discipline-specific. If the remaining studies are classified according the above taxonomy, the most frequent are professions and applied sciences (34\%), followed by humanities (16\%), formal sciences (11\%), social sciences (3\%), 
and natural sciences (3\%). In terms of individual sub-disciplines, languages and linguistics was the most common focus (35 studies), followed by education ( 28 studies), computer science (26 studies), and health sciences (26 studies).

Table 5

Distribution of Disciplines and Sub-disciplines

\begin{tabular}{|c|c|c|}
\hline Discipline & Subject & $\begin{array}{l}\text { Number of } \\
\text { studies }\end{array}$ \\
\hline \multirow[t]{7}{*}{ 1. Humanities (16\%) } & 1.1 History & 0 \\
\hline & 1.2 Languages and Linguistics & 35 \\
\hline & 1.3 Literature & $\mathrm{o}$ \\
\hline & 1.4 Performing Arts & $\mathrm{O}$ \\
\hline & 1.5 Philosophy & $\mathrm{O}$ \\
\hline & 1.6 Religion & 1 \\
\hline & 1.7 Visual Arts & 3 \\
\hline \multirow{10}{*}{$\begin{array}{l}\text { 2. Social Sciences } \\
\text { (3\%) }\end{array}$} & 2.1 Anthropology & 0 \\
\hline & 2.2 Archaeology & 0 \\
\hline & 2.3 Area Studies & $\mathrm{O}$ \\
\hline & 2.4 Cultural \& Ethnic Studies & 1 \\
\hline & 2.5 Economics & $\mathrm{O}$ \\
\hline & 2.6 Gender \& Sexuality Studies & 0 \\
\hline & 2.7 Geography & 3 \\
\hline & 2.8 Political Science & 0 \\
\hline & 2.9 Psychology & 2 \\
\hline & 2.10 Sociology & 2 \\
\hline \multirow{5}{*}{$\begin{array}{l}\text { 3. Natural Sciences } \\
(3 \%)\end{array}$} & 3.1 Space Sciences & 1 \\
\hline & 3.2 Earth Sciences & 2 \\
\hline & 3.3 Life Sciences & 1 \\
\hline & 3.4 Chemistry & 2 \\
\hline & 3.5 Physics & 0 \\
\hline \multirow{5}{*}{$\begin{array}{l}\text { 4. Formal Sciences } \\
(11 \%)\end{array}$} & 4.1 Computer Science & 26 \\
\hline & 4.2 Logic & 0 \\
\hline & 4.3 Mathematics & 2 \\
\hline & 4.4 Statistics & $\mathrm{O}$ \\
\hline & 4.5 Systems Science & $\mathrm{O}$ \\
\hline \multirow{17}{*}{$\begin{array}{l}\text { 5. Professions / } \\
\text { Applied Sciences } \\
(34 \%)\end{array}$} & 5.1 Agriculture & $\mathrm{O}$ \\
\hline & 5.2 Architecture \& Design & 5 \\
\hline & 5.3 Business & 12 \\
\hline & 5.4 Divinity & 0 \\
\hline & 5.5 Education & 28 \\
\hline & 5.6 Engineering & 8 \\
\hline & 5.7 Environmental Studies and Forestry & 1 \\
\hline & 5.8 Family and Consumer Science & 0 \\
\hline & 5.9 Health Sciences & 26 \\
\hline & 5.10 Human Physical Performance and Recreation & $\mathrm{O}$ \\
\hline & 5.11Journalism, Media Studies and Communication & 1 \\
\hline & 5.12 Law & 0 \\
\hline & 5.13 Library and Museum Studies & 2 \\
\hline & 5.14 Military Science & $\mathrm{O}$ \\
\hline & 5.15 Public Administration & o \\
\hline & 5.16 Social Work & 0 \\
\hline & 5.17 Transportation & 0 \\
\hline $\begin{array}{l}\text { Generic (Across } \\
\text { Disciplines) (30\%) }\end{array}$ & Generic (Across Disciplines) & 81 \\
\hline
\end{tabular}


In terms of comparison with studies from 2001-2010, these findings closely align to the studies by Hwang and Tsai (2011) and Wu et al. (2012). Wu et al. (2012) found that the most common disciplines to be professions and applied sciences (29\%), humanities (20\%), and formal sciences (16\%). Similar to findings by Hwang and Tsai (2011), a significant proportion of studies do not focus on a specific discipline, but are generic or across disciplines. Thus, it can be seen that mobile learning continues to be applied across most disciplines and that researchers from different disciplines can collaborate. In terms of sub-disciplines or subjects, the present study has similar findings that languages and linguistics, computer science, and health sciences are well represented. Language and health science educators seem to be more eager to adopt the affordances of mobile learning, where practical benefits can be seen for students. Mobile-assisted language learning (MALL) is a particularly growing area (Viberg \& Gronlund, 2013; Wu, 2015). The present study shows that the education discipline has become more of a focus for researchers. It is theorised that educators in computer science and education may be more prone to take advantage of technological innovations in learning. Nonetheless, more studies are required that show how mobile learning is adopted in other academic subjects. For future research at a category level, it is recommended that more research studies be conducted in the natural and social sciences.

\section{Research Settings}

Figure 3 shows the distribution of research settings. The categories of research settings were adapted from Song (2014) and Zheng, Huang, \& Yu (2014). Most often, research was carried out in both in class and out of class settings (33\%), followed by research carried out in class settings (16\%) and research conducted across settings (15\%). Research also took place in field settings, out of class settings, and in distance settings. More studies are needed in the future that focus on learner mobility and transitions across different settings.

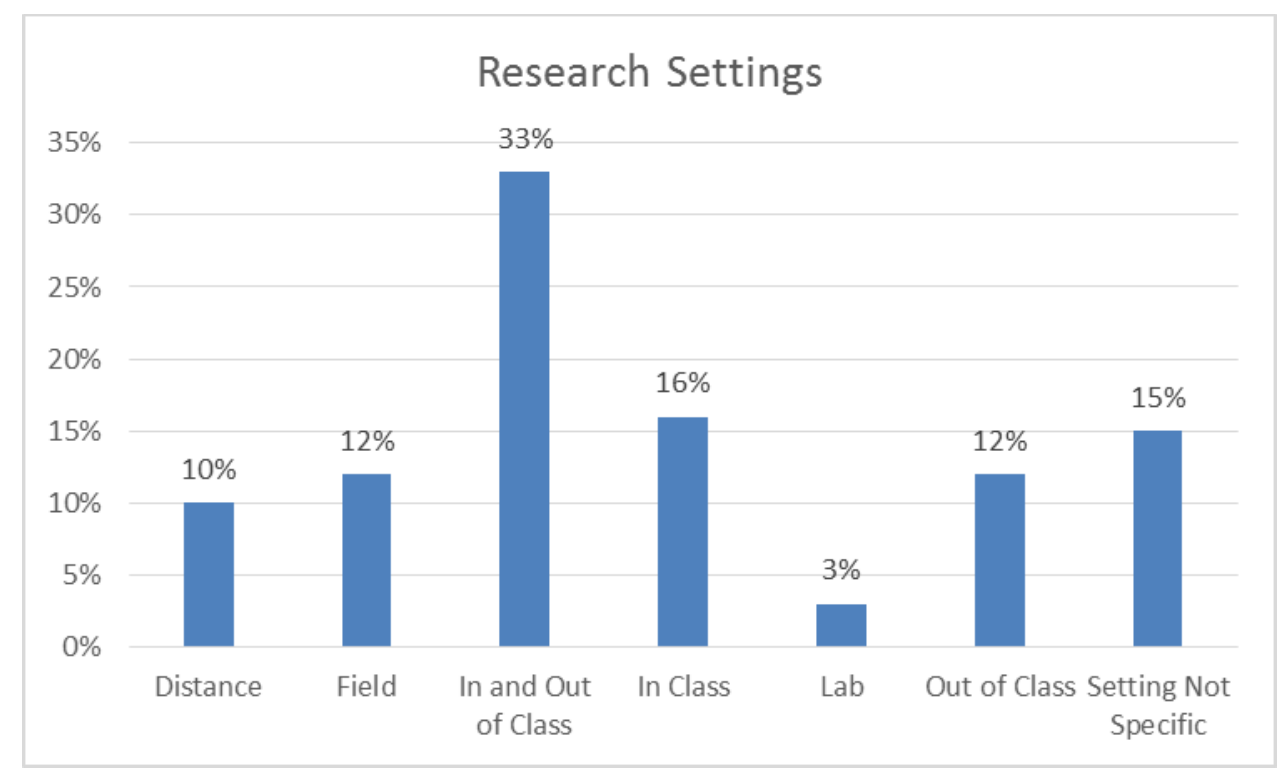

Figure 3. Distribution of studies by research setting.

No comparison can be done with the research studies from 2001-2010 as research settings were not a specific focus of the studies of Hwang and Tsai (2011), Hung and Zhang (2012), and Wu et al. (2012). 


\section{Devices}

Figure 4 shows the distribution of mobile devices used in the studies from 2011 to 2015. As indicated, the majority of studies (107) studied non-specific / generic mobile devices or learning across mobile devices. This may indicate that as technology changes so quickly, it may be best not to invest in a specific device as mobile learning can take place across a multitude of devices. This result may also be indicative of the growing realisation of Bring-Your-Own-Device (BYOD) (Cochrane, Antonczak, Keegan, \& Narayan, 2014; Traxler, 2016). If one looks at the specific device trends, it is clear that mobile phones (including smartphones) are the most frequently used devices in studies (73). It must be noted that 38 of the 73 studies using mobile phones specified the use of smartphones in particular. Tablets are also very frequently used in studies (33). For those studies that reported the specific brand of tablet, the Apple iPad was the overwhelmingly most used tablet brand.

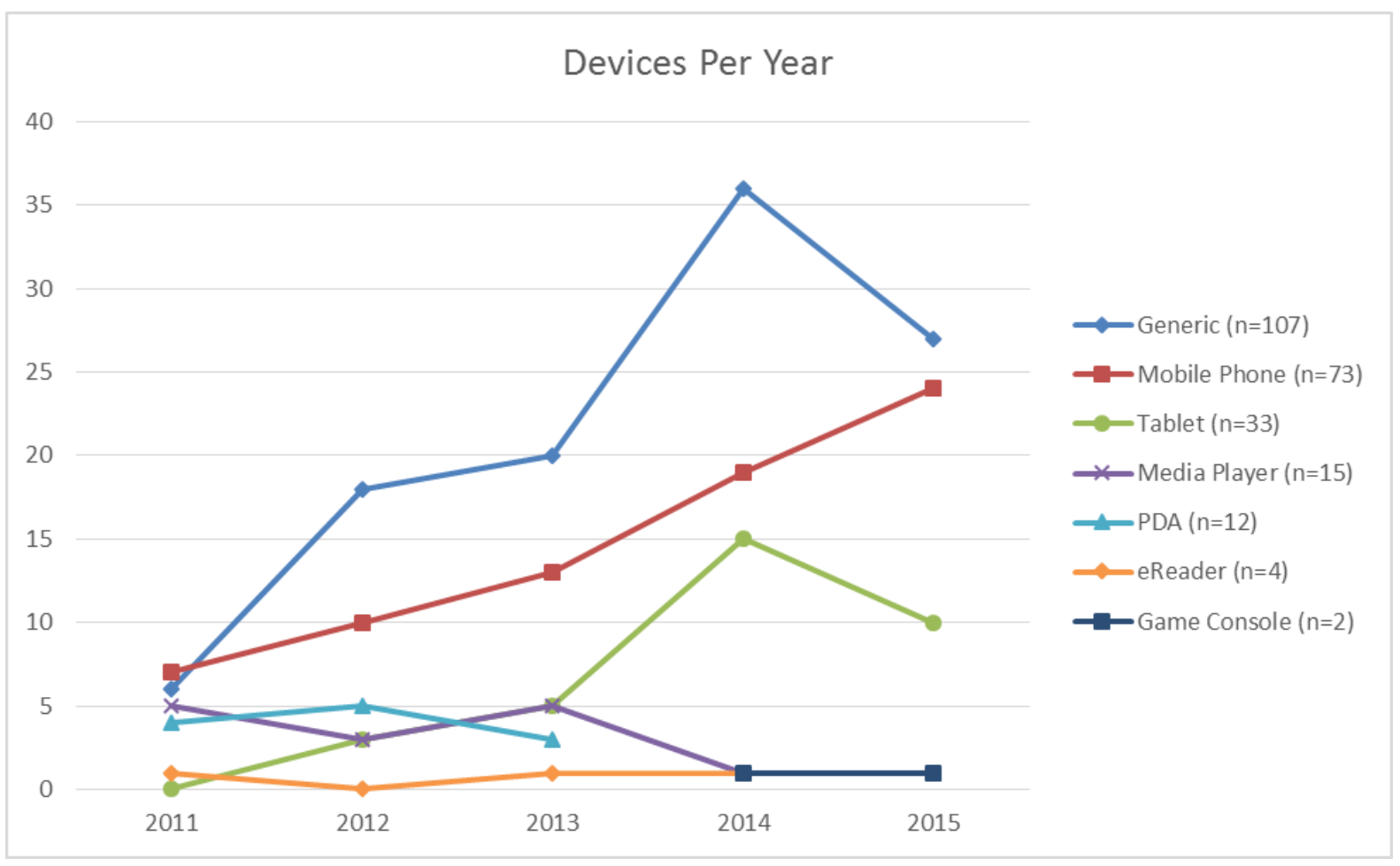

Figure 4. Distribution of devices by year.

In terms of comparison with studies from 2001-2010, the results demonstrate the changes in available technologies since the study conducted by Wu et al. (2012). However, mobile phones are still the most common devices used in studies. An increasing number of studies have focused on the use and affordances of smartphones (for example, the use of specific apps) rather than basic phones and features (for example, text messaging). Changes in available devices and emerging technologies influence the studies that are conducted. For example, previous studies made significant mention of PDA devices, whereas in the more recent studies from 2011-2013, these are seldom mentioned, and not mentioned at all in 2014-2015 studies. Tablet devices, particularly the Apple iPad, launched in 2010, have become much more prevalent. 


\section{Discussion}

The results of this study reveal research trends and issues in mobile learning in higher education. Mobile learning continues to be a growing area of research in higher education as evidenced by the number of academic articles published between 2011 and 2015 and the number of countries where this research was conducted. Forty-five countries were represented in this study. The results of this study have several implications for future research in mobile learning in higher education.

\section{Need for Expansion of Focus of Research Themes}

The most common research purpose was found to be evaluating the effectiveness of mobile learning (24\%), followed by the design of a mobile system for learning (23\%). This study found that the three most common research themes together (mobile applications and systems; socio-cultural contexts; and tools and technologies) account for almost half of the mobile learning studies in higher education (48\%). Figure 5 shows the research themes according to research purpose. This figure shows that there are several themes that are underrepresented in current studies. Consideration of those themes that have fewer studies should lead to researcher reflection and more studies in those areas to lead to a more complete understanding of the field. As a growing research field, the themes within mobile learning in higher education will change over time. However, several themes merit specific attention. More research and practice is required in themes related to innovative approaches (such as context-awareness services, augmented reality, and gamification). Additionally, studies that focus on learner mobility and transitions across different settings are areas where more research is needed. Finally, the use of newer technologies such as cloud computing and learning analytics may become greater themes of focus for researchers. 


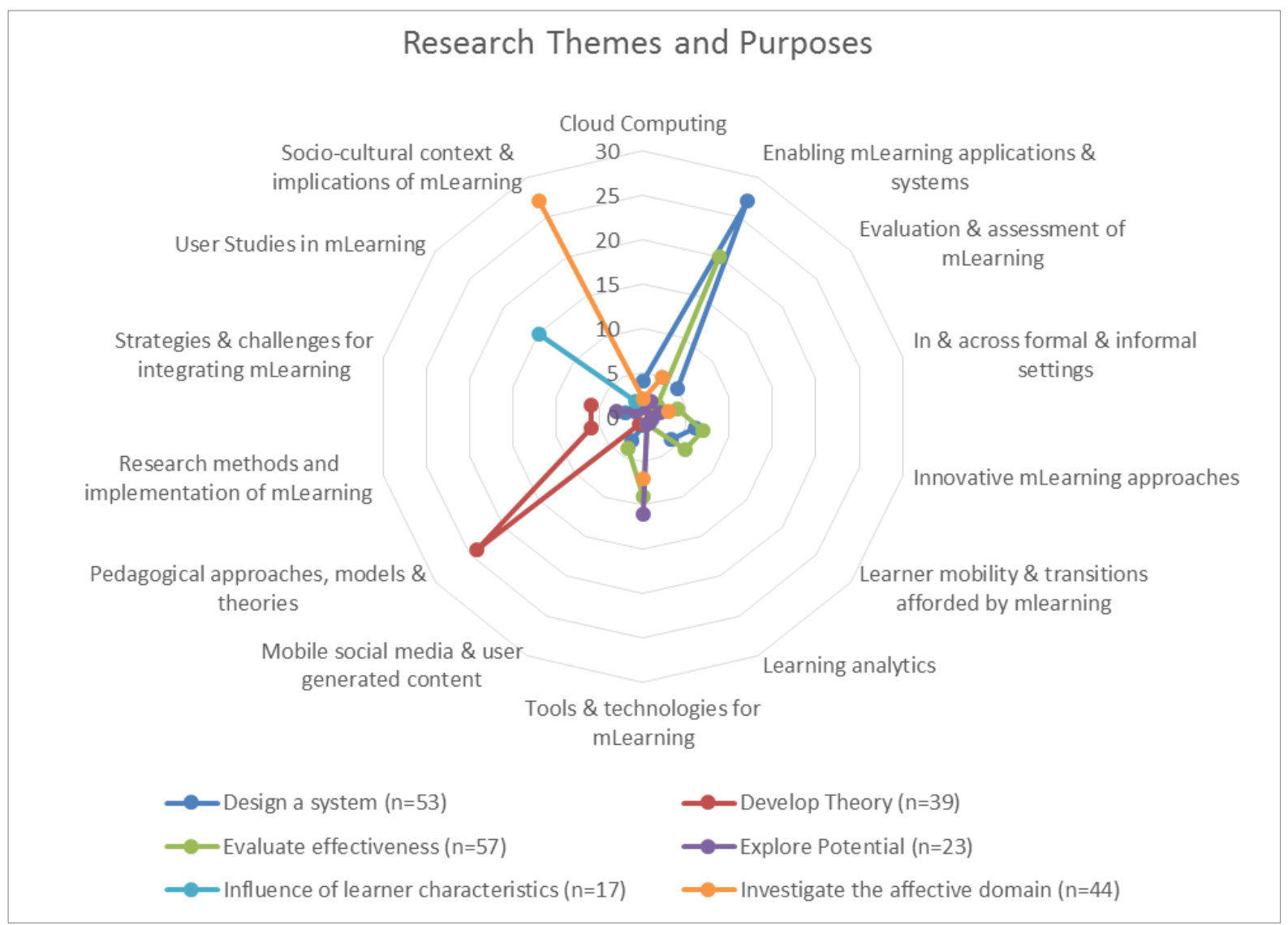

Figure 5. Research themes and purposes radar chart.

\section{Promotion of Variety in Research Design}

In terms of research methodology, both qualitative (46\%) and quantitative (43\%) approaches were used most often, with the remainder of studies utilizing a mixed methods approach. A variety of research designs were employed by researchers; the most common data collection methods were surveys (47\%), interviews/focus groups (18\%), and assessments (13\%). These findings align closely with studies from 2001-2010, but it appears that a wider variety of methods are increasingly being utilised. For future studies, it is recommended that authors are clear in describing the methodology used in their studies and include the theoretical/conceptual background, research design, data collection methods, data analysis approach, population groups, academic discipline, and research setting. Due to the various research topics and approaches in this expanding research field, there is a need for a wide range of research designs. However, the authors would like to point out that more studies in the future should look to make use of mixed methods research approaches. These approaches can combine the strengths of quantitative and qualitative methodologies. It is further recommended that more longitudinal studies are required, as well as studies across more than one individual course in order to understand the longterm effects and impact of mobile learning initiatives. This will also assist with understanding issues around sustainability and scale. Fewer studies are required that compare the mode of teaching and learning (mobile learning or e-learning). This is because of the many variable conditions within a mode of teaching and learning. Researcher attempts to keep all other conditions the same, can lead to a suppression of the conditions that may flourish in a particular mode (Bates \& Sangra, 2011).

\section{Growth of Bring-Your-Own-Device (BYOD) and Multiple Devices}


A key finding from the study was that a significant proportion of studies did not focus on a specific device for learning, and instead focused on a generic device or on multiple devices. For studies where a device was specified, mobile phones (including smartphones) were the devices most commonly used in studies, followed by tablets. Increasingly, educators and researchers cannot rely on funding for studies where students or staff are provided with specific devices for learning. Further studies are required that look at the personal devices that students have access to and how they access content and university services from these devices. However, BYOD goes beyond access to devices as students are no longer limited to institutional systems, but increasingly have their own internet access and make use of their own services. Devices are important, but the associated systems and networks are equally significant (Traxler, 2016). Access and use of these devices by a majority of students presents challenges and opportunities for the support and provision of learning (Traxler, 2010). Further research is required in how BYOD strategies are incorporated into university teaching and learning and the provision of associated academic and technological support. For the successful integration of mobile learning, faculty need to critically assess the use of mobile devices for learning and design specific learning experiences that take advantage of the affordances of mobile devices. Otherwise, mobile learning may continue to be restricted to viewing a mobile version of an institutional learning management system. Very often, students have access to more than one personal device. Students may use of multiple devices and these devices can change over time. New technologies arrive all the time, enabling faculty and students to explore new ways to learn with these tools (Parsons, 2014). For example, future studies may focus on the impact of wearable technologies in learning.

\section{Focus on Sustainability and Mainstreaming of Mobile Learning}

Increasingly, advanced mobile technologies have become integrated into society, but despite the potential, have not yet been "fully and formally integrated into higher education" (Traxler, 2016, "Looking backward", para. 3). Many innovative research projects in mobile learning in the last 15 years did not extend beyond pilot projects to become embedded or mainstreamed in education, in part because of financial and cultural barriers (Traxler, 2016). Further research into how mobile learning studies can be scaled up or embedded into higher education institutions would be useful. It is expected that in the next 10 years, mobile technologies will continue to become more popular, personal, and social. This means that mobile and connected learners can potentially change the nature of teaching and learning. With the aid of mobile technologies, students can easily "generate, store, share, discuss and consume images, ideas, information and opinions, can access the cloud, and the services it provides, and can access each other" (Traxler, 2016, "Looking forward," para. 8). Often this takes place outside of institutional systems and applications. This has profound implications for how faculty design courses and facilitate learning.

\section{Conclusion}

Similar to previous review studies, this research aims to provide analysis and guidance for the selection of research topics and methods within mobile learning (Hung \& Zhang, 2012). Systematic reviews can generate suggestions and insightful implications for researchers and educators aiming to provide meaningful mobile learning experiences and environments (Hsu \& Ching, 2015). The reviews of Hwang and Tsai (2011), Hung and Zhang (2012), and Wu et al. (2012) applied to research studies from 2001 until 2010. This study examined articles from 2011 to 2015 as follow up research to consider the 
similarities and differences in an expanding field. This research focused solely on the higher education context. Following a search of three academic databases, 233 peer-reviewed articles were selected and organised for review. The researchers used content analysis to analyse the data around categories related to research purpose, theme, method, target population, setting, device, and others. In comparison with previous reviews, similarities were found with regard to research purposes and research methods used.

Key findings indicate that researchers conduct studies in mobile learning in higher education for a variety of reasons, but that evaluating the effectiveness is the most common purpose. Similarly, a variety of themes within mobile learning are explored, but the most common topic focuses on enabling applications and systems. An increasing number of studies have focused on the use and affordances of smartphones (for example, the use of specific apps) rather than basic phones and features (for example, text messaging). Newer research topics relate to mobile learning and social networking, games and augmented reality. Research methods are split between quantitative and qualitative methods. Data collection continues to focus primarily on surveys, but a wider variety of methods is being utilised. A significant proportion of studies do not focus on a specific mobile device, but across devices in mobile learning. The research shows the increasing trend of BYOD. Mobile phones are still the most common devices used in mobile learning studies (including smartphones), but tablets are increasingly popular. A significant change is occurring through BYOD, where learning with multiple personal devices is possible.

\section{References}

Ally, M., \& Prieto-Blázquez, J. (2014). What is the future of mobile learning in education? The International Journal of Educational Technology in Higher Education, 11(1), 142-151. https://doi.org/10.7238/rusc.v11i1.2033

Alrasheedi, M., \& Capretz, L. F. (2015). Determination of critical success factors affecting mobile learning: A meta-analysis approach. Turkish Online Journal of Educational Technology, 14(2), 41-52. Retrieved from http://tojet.net/articles/v14i2/1426.pdf

Arpaci, I. (2015). A comparative study of the effects of cultural differences on the adoption of mobile learning. British Journal of Educational Technology, 46(4), 699-712. https://doi.org/10.1111/bjet.12160

Baran, E. (2014). A review of research on mobile learning in teacher education. Educational Technology \& Society, 17(4), 17-32. Retrieved from http://www.ifets.info/journals/17 4/2.pdf

Bartel, A., \& Hagel, G. (2014). Engaging students with a mobile game-based learning system in university education. International Journal of Interactive Mobile Technologies, 8(4), 95796o. https://doi.org/10.3991/ijim.v8i4.3991 
transforming teaching and learning. San Francisco, CA: John Wiley \& Sons.

Becher, T. (1994). The significance of disciplinary differences. Studies in Higher Education, 19(2), 151-161. https://doi.org/10.1080/03075079412331382007

Bernard, R. M., Borokhovski, E., \& Tamim, R. M. (2014). Detecting bias in meta-analyses of distance education research: big pictures we can rely on. Distance Education, 35(3), 271-293. https://doi.org/10.1080/01587919.2015.957433

Bogdanović, Z., Barać, D., Jovanić, B., Popović, S., \& Radenković, B. (2014). Evaluation of mobile assessment in a learning management system. British Journal of Educational Technology, 45(2), 231-244. https://doi.org/10.1111/bjet.12015

Bozkurt, A., Akgun-Ozbek, E., Yilmazel, S., Erdogdu, E., Ucar, H., Guler, E., ... Hakan Aydin, C. (2015). Trends in distance education research: A content analysis of journals 2009-2013. The International Review of Research in Open and Distributed Learning, 16(1), 330-363. https://doi.org/10.19173/irrodl.v16i1.1953

Brown, T. H., \& Mbati, L. S. (2015). Mobile learning: Moving past the myths and embracing the opportunities. The International Review of Research in Open and Distributed Learning, 16(2), 115-135. https://doi.org/10.19173/irrodl.v16i1.1953

Calma, A., Webster, B., Petry, S., \& Pesina, J. (2014). Improving the quality of student experience in large lectures using quick polls. Australian Journal of Adult Learning, 54(1), 114-136.

Cheung, W. S., \& Hew, K. F. (2009). A review of research methodologies used in studies on mobile handheld devices in K-12 and higher education settings. Australasian Journal of Educational Technology, 25(2), 153-183. https://doi.org/10.14742/ajet.1148

Churchill, D., \& Wang, T. (2014). Teacher's use of iPads in higher education. Educational Media International, 51(3), 214-225. doi: https://doi.org/10.1080/09523987.2014.968444

Cochrane, T., Antonczak, L., Keegan, H., \& Narayan, V. (2014). Riding the wave of BYOD: developing a framework for creative pedagogies. Research in Learning Technology, 22, 1-15. https://doi.org/10.3402/rlt.v22.24637

Cochrane, T. D. (2014). Critical success factors for transforming pedagogy with mobile Web 2.o. British Journal of Educational Technology, 45(1), 65-82. https://doi.org/10.1111/j.14678535.2012.01384.x

Creswell, J. W. (2009). Research design: Qualitative, quantitative and mixed methods approaches (3rd ed.). Thousand Oaks, CA: Sage Publications.

Dennen, V. P., \& Hao, S. (2014). Intentionally mobile pedagogy: The M- COPE framework for mobile learning in higher education. Technology, Pedagogy and Education, 23(3), 397-419. https://doi.org/10.1080/1475939X.2014.943278

Elo, S., \& Kyngäs, H. (2008). The qualitative content analysis process. Journal of Advanced Nursing, 
62(1), 107-115. https://doi.org/10.1111/j.1365-2648.2007.04569.x

Engin, M., \& Donanci, S. (2015). Dialogic teaching and iPads in the EAP classroom. Computers \& Education, 88, 268-279. https://doi.org/10.1016/j.compedu.2015.06.005

Fonseca, D., Martí, N., Redondo, E., Navarro, I., \& Sánchez, A. (2014). Relationship between student profile, tool use, participation, and academic performance with the use of Augmented Reality technology for visualized architecture models. Computers in Human Behavior, 31, 434-445. https://doi.org/10.1016/j.chb.2013.03.006

Frohberg, D., Göth, C., \& Schwabe, G. (2009). Mobile Learning projects - a critical analysis of the state of the art. Journal of Computer Assisted Learning, 25(4), 307-331. https://doi.org/10.1111/j.1365-2729.2009.00315.x

Gikas, J., \& Grant, M. M. (2013). Mobile computing devices in higher education: Student perspectives on learning with cellphones, smartphones \& social media. Internet and Higher Education, 19, 18-26. https://doi.org/10.1016/j.iheduc.2013.06.002

Hsu, Y. C., \& Ching, Y. H. (2012). Mobile microblogging: Using twitter and mobile devices in an online course to promote learning in authentic contexts. The International Review of Research in Open and Distributed Learning, 13(4), 211-227. https://doi.org/10.19173/irrodl.v13i4.1222

Hsu, Y.-C., \& Ching, Y.-H. (2015). A review of models and frameworks for designing mobile learning experiences and environments. Canadian Journal of Learning and Technology, 41(3), 1-22. https://doi.org/10.21432/T2V616

Hsu, Y.-C., Ching, Y.-H., \& Snelson, C. (2014). Research priorities in mobile learning: An international Delphi study. Canadian Journal of Learning and Technology, 4O(2). https://doi.org/10.21432/T2QP4X

Hung, J. L., \& Zhang, K. (2012). Examining mobile learning trends 2003-2008: A categorical metatrend analysis using text mining techniques. Journal of Computing in Higher Education, 24(1), 1-17. https://doi.org/10.1007/s12528-011-9044-9

Hwang, G.-J., \& Tsai, C.-C. (2011). Research trends in mobile and ubiquitous learning: a review of publications in selected journals from 2001 to 2010. British Journal of Educational Technology, 42(4), E65-E70. https://doi.org/10.1111/j.1467-8535.2011.01183.x

Institute of Education Sciences. (2010). Classification of instructional programs (CIP). Retrieved from: https://nces.ed.gov/ipeds/cipcode/default.aspx?y=55

Lim, T., Fadzil, M., \& Mansor, N. (2011). Mobile learning via SMS at Open University Malaysia: Equitable, effective and sustainable. The International Review of Research in Open and Distributed Learning, 12(2), 122-137. https://doi.org/10.19173/irrodl.v12i2.926

Lin, S., Zimmer, J. C., \& Lee, V. (2013). Podcasting acceptance on campus: The differing perspectives of teachers and students. Computers and Education, 68, 416-428. https://doi.org/10.1016/j.compedu.2013.06.003 
Liu, M., Scordino, R., Geurtz, R., Navarrete, C., Ko, Y., \& Lim, M. (2014). A look at research on mobile learning in $\mathrm{K}-12$ education from 2007 to the present. Journal of Research on Technology in Education, 46(4), 325-372. https://doi.org/10.1080/15391523.2014.925681

Lu, C., Chang, M., Kinshuk, Huang, E., \& Ching-Wen, C. (2014). Context-aware mobile role playing game for learning - A case of Canada and Taiwan. Journal of Educational Technology \& Society, 17(2), 101-101?114. Retrieved from http://www.ifets.info/journals/17 2/9.pdf

Mac Callum, K., Jeffrey, L., \& Kinshuk (2013). The influence of students' ICT skill and their adoption of mobile learning. Australasian Journal of Educational Technology, 29(3), 303-314. https://doi.org/10.14742/ajet.298

Naismith, L., Lonsdale, P., Vavoula, G., \& Sharples, M. (2004). Literature review in mobile technologies and learning (Futurelab Series Report 11). Bristol: Futurelab.

O'Malley, C., Vavoula, G., Glew, J. P., Taylor, J., Sharples, M., Lefrere, P., ... \& Waycott, J. (2005). Guidelines for learning/teaching/tutoring in a mobile environment. Public deliverable from the MOBILearn project (D.4.1). Retrieved from https://hal.archives-ouvertes.fr/hal$\underline{00696244}$

Park, Y. (2011). A pedagogical framework for mobile learning: Categorizing educational applications of mobile technologies into four types. The International Review of Research in Open and Distributed Learning, 12(2), 78-102. https://doi.org/10.19173/irrodl.v12i2.791

Parsons, D. (2014). A mobile learning overview by timeline and mind map. International Journal of Mobile and Blended Learning, 6(4), 1-20. https://doi.org/10.4018/ijmbl.2014100101

Redondo, E., Fonseca, D., Sánchez, A., \& Navarro, I. (2014). Mobile learning in the field of Architecture and Building Construction. A case study analysis. The International Journal of Educational Technology in Higher Education, 11(1), 152-174. https://doi.org/10.7238/rusc.v11i1.1844

Reychav, I., Kobayashi, M., \& Dunaway, M. (2015). Understanding mobile technology-fit behaviors outside the classroom. Computers \& Education, 87, 142-150. https://doi.org/10.1016/j.compedu.2015.04.005

Song, Y. (2014). Methodological issues in mobile computer-supported collaborative learning (mCSCL): What methods, what to measure and when to measure? Educational Technology \& Society, 17(4), 33-48. Retrieved from http://www.ifets.info/journals/17 4/3.pdf

Tabuenca, B., Kalz, M., Drachsler, H., \& Specht, M. (2015). Time will tell: The role of mobile learning analytics in self-regulated learning. Computers \& Education, 89, 53-74. https://doi.org/10.1016/j.compedu.2015.08.004

Traxler, J. (2010). Students and mobile devices. Research in Learning Technology, 18(2), 149-160. https://doi.org/10.1080/09687769.2010.492847

Traxler, J. (2016). Inclusion in an age of mobility. Research in Learning Technology, 24. https:// 
doi.org/10.3402/rlt.v24.31372

Viberg, O., \& Gronlund, A. (2013). Cross-cultural analysis of users' attitudes toward the use of mobile devices in second and foreign language learning in higher education: A case from Sweden and China. Computers \& Education, 69, 169-180. https://doi.org/10.1016/j.compedu.2013.07.014

Wang, M., Chen, Y., \& Khan, M. J. (2014). Mobile cloud learning for higher education: A case study of moodle in the cloud. The International Review of Research in Open and Distributed Learning, 15(2), 254-267. https://doi.org/10.19173/irrodl.v15i2.1676

Wanner, R. A., Lewis, L. S., \& Gregorio, D. I. (1981). Research productivity in academia: A comparative study of the sciences, social sciences and humanities. Sociology of Education, 54(4), 238-253. https://doi.org/10.2307/2112566

Wingkvist, A., \& Ericsson, M. (2011). A survey of research methods and purposes in mobile learning. International Journal of Mobile and Blended Learning, 3(1), 1-17. https://doi.org/10.4018/jmbl.2011010101

Wong, L. H., \& Looi, C. K. (2011). What seams do we remove in mobile-assisted seamless learning? A critical review of the literature. Computers and Education, 57(4), 2364-2381. https://doi.org/10.1016/j.compedu.2011.06.007

Wu, P., Hwang, G.-J., Su, L., \& Huang, Y. (2012). A context-aware mobile learning system for supportive cognitive apprenticeships in nursing skills training. Educational Technology \& Society, 15(1), 223-236. Retrieved from http://www.ifets.info/journals/15 1/20.pdf

Wu, Q. (2015). Designing a smartphone app to teach English (L2) vocabulary. Computers \& Education, 85, 170-179. https://doi.org/10.1016/j.compedu.2015.02.013

Wu, W. H., Jim Wu, Y. C., Chen, C. Y., Kao, H. Y., Lin, C. H., \& Huang, S. H. (2012). Review of trends from mobile learning studies: A meta-analysis. Computers and Education, 59(2), 817-827. https://doi.org/10.1016/j.compedu.2012.03.016

Zheng, L., Huang, R., \& Yu, J. (2014). Identifying computer-supported collaborative learning (CSCL) research in selected journals published from 2003 to 2012: A content analysis of research topics and issues. Educational Technology \& Society, 17(4), 335-351. Retrieved from http://www.ifets.info/journals/17_4/23.pdf

\section{Athabasca University}

